\title{
sciendo
}

\section{Seeking freelancers' motivations to adopt an entrepreneurial career - a storytelling approach}

\author{
Daniela DAMIAN \\ "Dunarea de Jos" University of Galati, Romania \\ danah2030@yahoo.com \\ Alexandru CAPATINA \\ "Dunarea de Jos" University of Galati, Romania \\ acapatana@ugal.ro
}

\begin{abstract}
The article focuses on worldwide freelancers' stories as explanatory resources in understanding their reasons to embrace or not an entrepreneurial career in the future. It draws upon a qualitative study related on the motivations, benefits and risks of moving from freelancing to an entrepreneurial career, where participants to the survey freely expressed their perceptions, based on their genuine experiences. Data collected during the online survey have been analyzed with NVivo12 software. This qualitative analysis software allowed us to cluster the narratives of freelancers, based on the similarity of words contained in content, on the one hand, and provided a deeper understanding of sentiments related to freelancers' intention to turn entrepreneurs, on the other hand. Following two principles: "No need to invent or reinvent yourself" and "Real life truths have the most impact", freelancers who accepted our invitation to the survey highlighted their visions regarding the future career paths, providing an approach to understand their choice to become or not entrepreneurs. Freelancers' career path can be more comprehensively described, understood and communicated using their stories, so storytelling has been considered the single methodology appropriate to this study objectives. Practical implications of this qualitative research, its limitations and further research avenues are also highlighted.
\end{abstract}

Keywords: freelancing, entrepreneurship, career development, storytelling

\section{Introduction}

This paper aims to analyze the possible freelancers' career trajectories and the story behind each freelancer, the ways to manage their own working time, their vision of the future when it comes to their careers, the risks associated with their long-term career in freelancing, and the possibility of embarking on a career in entrepreneurship. The central research problem refers especially to freelancers who have accepted the invitation to this study and who have highlighted their visions of future career paths, offering their own approach to understand their choice to either become an entrepreneur or not. Consequently, this research takes into account aspects such as the benefits, motivations and the risks they face when moving from freelancing to entrepreneurship.

In Romania in 2015 , there were about 400,000 freelancers, by $12.5 \%$ more than in 2010 . In other words, about one in ten Romanians gained revenues from independent contracts, and the percentage is steadily growing.

Online freelancing platforms, which have opened opportunities for people from all over the world, are the most important incentive for the freelance economy. For example, UpWork, the largest platform of this type in the world, has about 12 million registered freelancers.

Of these, most of them are Americans (over one million), Indians (around 650,000) and Filipinos (approximately 180,000). Romania, with about 45,000 freelancers offering their 
services, is on the 9th place in the top of platform users. (https://revistacariere.ro/inspiratie/cum-sa/tinerii-romani-nu-mai-stau-opt-ore-la-birousi-devin-freelanceri/)

\section{Literature review}

The modern dynamic economy is closely associated with freelancers through core attributes such as portfolio work, discontinuous and contingent labour contracts, self-employment and outsourcing (Handy, 1984; 1989). The Oxford English dictionary defines the word freelance as a "person working for no fixed employer" (Waite, 1998, p. 253). Wikipedia defines a freelancer as "somebody who is self-employed and not committed to a particular employer long term". Essentially freelance workers hire out their labour services on a project by project basis. http://en.wikipedia.org/wiki/Freelancer.

The traditional research focus of academics on vulnerability side of the low skilled freelancers does not resonate with the labour market performance of more highly skilled freelancers, who are innovative and earn significantly higher income than employees (Burke, 2015).

Du Gay et al (1996) argue that the defining feature of freelance work is that it is a transactional short-term contract where the employer does not take responsibility for the personal development and employment career of the worker. Freelancers are usually paid on the basis of their productivity (output of their work) rather than the more commonly used approach in continuous employment where workers are paid on a time input basis (e.g. weekly wage or month salary).

Freelancers account for a significant proportion of economic activity. In order to estimate the size of the freelance economy, Kitching and Smallbone (2008) propose a broad definition of freelancers as all self-employed workers and directors of limited companies without employees.

There is also an entrepreneurship literature where freelancers are not classified as workers but by virtue of being self-employed are viewed as owner managers who do not (yet) have any employees. Since high performing entrepreneurs are usually characterised by job creation - where high growth job creators are often referred to as 'gazelles' - the freelance 'one man bands' then comprise the lowest end of the entrepreneurial performance spectrum. They are then depicted as failing or underperforming entrepreneurs. (Burke, 2011).

Freelancers, on the one hand, can be considered employed because they are employed by firms for a fixed period of time, providing their intangible professional knowledge and on the other hand they can be considered entrepreneurs because they carry out work based on their own risk and reward (Born and Witteloostuijin, 2013).

Digital technologies and the innovative business models are dramatically challenging freelancers' options for their future careers.

A person may prefer to work as a freelancer, being self-employed for reasons of high level expertise in a domain, self-fulfilment and self-realization. (Annink et al., 2016).

Freelancers have gained growing attention from business researchers with a particular focus on their behaviour, career paths, and entrepreneurship (Born and Witteloostuijn, 2013; Jang, 2017). 
Freelance workers represent a valuable pillar of the worldwide labour force, enabling clients from a wide variety of domains to hire them in order to meet operational requirements in a very flexible way.

The ongoing expansion of the freelance workforce reflects that access to a pool of skilled and motivated freelancers remains highly appreciated by clients (Kitching and Smallbone, 2015). However, freelancers' doors to entrepreneurship remain open, if they are really interested in the catalysing effect of management training on growth-related entrepreneurial attitudes (Schamp and Deschoolmeester, 1998).

In contrast, other opinions reflect that many organizations in recent years took wrong turns with the extensive use of freelancers, as the short-term cost-savings were more tempting in relation to the development of their own human capital resources (Luthans and Youssef, 2004).

Existing literature highlights an expanding trend in freelancing in terms of their growth and number of innovative service domains where freelancers are engaged in. For many persons, freelance activities are a desirable option, even if entrepreneurship appears as a tempting opportunity.

Although freelancers are satisfied with their way of working, their work includes only a few entrepreneurial characteristics and it seems that they would prefer to capture entrepreneurial opportunities in their future career (Bögenhold et al., 2014).

The results of a study conducted by Falco and Haywood (2016) challenge the researchers' minds with a central question: the rise in freelance activities is the result of improved opportunities for successful entrepreneurship, or the reflection of limited opportunities in wage-based employment. A freelancer who is very strong in professional knowledge and innovation capabilities, would not be well advised to become an entrepreneur because he would waste knowledge and potential earnings that he could earn as a self-employed person developing his strongest specified skills and accumulating experience and reputation (Backes-Gellner and Moog, 2013).

Most freelancers are engaged in online networks to increase the probability to find clients and sign contracts with them. In these networks, their experience, innovation skills and online reputation are valuable intangible assets appreciated by the clients (Saundry et al., 2007). This paper aims to analyze the possible freelance career trajectories and the story behind each freelancer, ways to manage their own working time, their vision of the future when it comes to their careers, the risks associated with their long-term career in freelancing, and the possibility of embarking on a career in entrepreneurship.

\section{Research methodology}

Mixed methods involve surveys in which a researcher or team of researchers combines elements of qualitative and quantitative research approaches (e.g., use of qualitative and quantitative viewpoints, data collection, analysis, inference techniques) for the broad purposes of breadth and depth of understanding and corroboration. (Johnson, Onwuegbuzie \& Turner, 2007)

Storytelling was applied as a methodology to investigate the following research question: why do freelancers intend to choose or not an entrepreneurial career to remain in long term relationship with the control over their workload and time? 
Nvivo 12 is a software enabling qualitative data analysis; in the current research, it aims at analysing the feelings underpinning the decision to work as a freelancer. Unlike quantitative research, Nvivo12 creates the opportunity to work with extensive text-based information, where deep levels of analysis of small or large data volumes are required (Bazeley and Jackson, 2013). Nvivo12 stores, sorts all data in a single platform, from comprehensible information to qualitative open-ended questions, easily transforms data, and visualizes results, to create ideas and discover new ways to investigate.

For this research, a smaller sample size was sufficient, involving 15 freelancers in online networks, with a significant degree of expertise for the configurational research design. The online questionnaire has been administrated via Google forms, the invitation link being: https://goo.gl/forms/wnUjIJSsdeG6ACd22.

The design framework highlights their feelings and vision based on the experience in freelancing, the risks and benefits associated with the next level, the common points between freelancers and entrepreneurs, while highlighting the right ways to move from freelancing to entrepreneurship.

The quality of the research depended entirely on the results of the freelancer's statements and on the influence of their stories. The direction and framework of research have often been revised, and as new information has been created, they have allowed us to thoroughly assess issues and subjects. One of the most important steps in the qualitative research process is the data analysis, and in this case we used the analysis of classical content, similar to the comparative analysis. Coding is another interpretive technique that organizes the data and provides means to introduce its interpretations into some quantitative methods.

\section{Results and discussions \\ Auto Code Sentiment Results}

Freelancers' answers to the questions have been codified and analysed using a rigorous approach based on a comparative analysis. In Figure 1, we used the auto-code wizard to automatically detect, automatically encode sentiment, quickly identify expression of sentiment in the content used, and to see if the overall tone of the content is positive or negative. Text analysis is a complex process, the human perception of sentiment will always be more accurate.

\begin{tabular}{|c|c|c|c|c|}
\hline \multirow[t]{2}{*}{ E:Eompared by number of coding } & \multicolumn{2}{|c|}{ it Results 12 x F Compared by number of sentim } & \multicolumn{2}{|l|}{ Fstorytelling } \\
\hline & A: Very negative $\quad \nabla$ & B: Moderately negative $\nabla$ & $C:$ Moderately positive $\nabla$ & D: Very positive \\
\hline 1: Nodes llstorytellingll1. Why a career in freelancing $\quad \nabla$ & 0 & 2 & 3 & 2 \\
\hline 2: Nodes llstorytellingll10. What is your vision, based o... $\nabla$ & 1 & 3 & 7 & 1 \\
\hline 3: Nodes Istorytelling|12. Do you think that freelancing ... $\nabla$ & 2 & 0 & 1 & 2 \\
\hline 4 : Nodes llstorytellingll3. Do you consider that there ar... $\nabla$ & 0 & 1 & 4 & 2 \\
\hline 5: Nodes $\|$ storytelling $\mid$ |4. From your experience gaine... $\nabla$ & 0 & 3 & 7 & 0 \\
\hline 6: Nodes llstorytellingl15. What are the benefits of mov... $\nabla$ & 0 & 0 & 6 & 2 \\
\hline $7:$ Nodes listorytellingll6. What are the risks of moving ... $\nabla$ & 3 & 10 & 3 & 0 \\
\hline 8: Nodes Istorytellingll7. Do you know freelancers wh... $\nabla$ & 1 & 0 & 1 & 0 \\
\hline 9: Nodes $\mid$ sstorytellingll8. When do you think it would b... $\nabla$ & 0 & 1 & 3 & 1 \\
\hline 10 : Nodes listorytelling 19 . If you take a look at the fina... $\nabla$ & 0 & 3 & 3 & 1 \\
\hline
\end{tabular}

Fig.1 Auto Code Sentiment Results

Source: data provided by NVivo 12 software 
The qualitative methodology of the study helped us to discover complex phenomena in their contexts. Each individual case is being analysed in depth, containing high levels of validity for qualitative research and obtaining single points from each respondent, their answers being not influenced by other freelancers.

The higher values are associated with the fact that there are risks in switching from freelancing to entrepreneurship, with the highest proportion of their answers being moderately negative. We give some examples of freelancers' narratives: "The risk is financial in the first place. If you move to an entrepreneurial career you need to have the budget and be prepared to bring more if necessary. The other risk is not to find people as good as you are and as you drive to do their job." "The main risk is to go bankrupt, losing money."

Switching to entrepreneurship involves more workload with more responsibilities, more efficient management of time and financial resources, permanent information on legislation and how to manage the business in the most sensible way. In a very small proportion, they believe that freelancing can be a starting point for an entrepreneurial career, the risk being that they have not gained enough experience as a freelancer to make the jump to entrepreneurship.

Nonetheless the benefits of moving from freelancing to an entrepreneurial career explain the theory that any opportunity to earn more money is welcome in the future, the results being moderately positive. The existence of a well-established business plan, of a market demand for the product or service offered, of a set of qualifications in a particular field can become a safe source of income and it is worth turning it into a business. But the most obvious benefit that could provide additional services to customers and which ultimately would turn into a larger cash flow is the potential to develop and refine each other's abilities.

From the experience gained on the platforms on which they operate, they believe that the ideal entrepreneur's profile is the person who has the necessary knowledge to run a business and gives time to employees working in his company. In freelancers' view, the ideal entrepreneur is the one who communicates with the employees and learns in every field in which works, the one who lets them do their job and appreciates the outcome at the end.

From data analysis, freelancers' response to the ideal entrepreneur model is one that continually innovates, their answers being moderately positive in most cases. One of the respondents was inspired by Ryan Holmes, a Canadian computer programmer and internet entrepreneur. Looking at the financial forecast of the market and implicitly their work, they firmly believe that freelancing is the future, considering that the free market will form the rest of the labour market.

More and more employers will offer more flexible working hours and days, they will focus more on reaching a deadline than on the working hours in a day. Freelancers make their own future by providing a service or product to people who need it. They consider freelancing to be the way to freedom by making them happy for working for themselves, each success being theirs and fully enjoying it.

In this context, there are many trends in the global job market, or in some sectors of activity involving freelancers in different projects, and a combination of freelancing and remote work is also present and future, their answers being equally moderately negative and moderately positive. 
This qualitative research has involved an observational examination of freelance philosophies, but also of the stories behind each. For each of them, freelance is a life choice. Being a freelancer does not mean to work from 9 to 17, but most of the time from 7 to 24 .

Most freelancers started their career in a multinational in Romania. Working in a multinational means working in a closed, busy, agitated, less airy space that leaves no time for family, for personal life, and does not give employees the chance to live in the present, always dreaming of what they would do if they were not at work.

\section{Spreading cases in a hierarchy chart}

The research design reveals the spread of cases in a hierarchy chart. The diagram shows hierarchical data as a set of rectangles of different sizes, using size to represent the amount of coding at each node. Size indicates the quantity, the number of coded nodes, or the amount of coding references. The hierarchy chart is sized to best fit the available space so that the dimensions of the rectangles are taken into account with respect to each other, and not as an absolute number. Larger areas are displayed at the top left of the graph and smaller rectangles are displayed on the bottom right.

Hierarchy tables are aggregated data. Each node is represented on the hierarchical diagram. We used the colour and size to display information about this research. The reference number has been dimensioned and coloured for coding. All 10 questions were highlighted with a light colour, freelancers in most cases gave a neutral response and have the most coding references, so they represent the largest area (Figure 2).

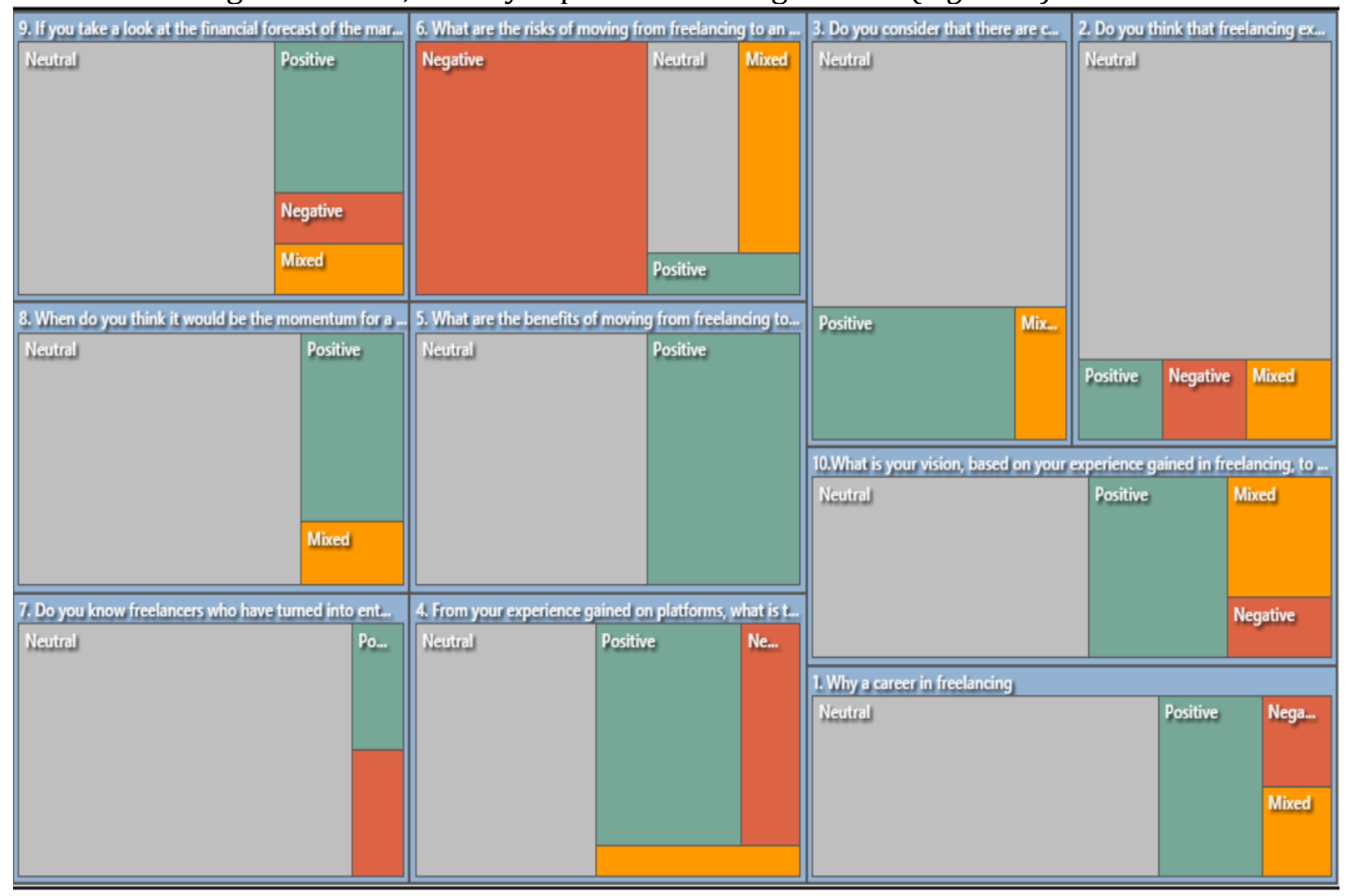

Fig 2. Spreading cases in a hierarchy chart

Source: data provided by NVivo 12 software 
Positive answers projected in the diagram have fewer coding references and have a darker colour in the hierarchy chart. At the same time, it shows us that they are more positive about freelancing, the common points between freelancers and entrepreneurs, the freedom to choose their own projects, the personal life and the flexibility in their work.

Negative answers marked with dark red highlight the fact that the vast majority of freelancers already see themselves as small entrepreneurs and currently do not want a career in entrepreneurship, highlighting firstly the financial risks to which they can be exposed as well as time management.

To the question "What are the risks of moving from freelancing to an entrepreneurial career?" most of them have responded to "too many risks", "at first, it's hard financially," "the main risk is going bankrupt," "financial ruin". Platforms give them the freedom to live and work where and how they want. Their program depends on no one but on the decisions they make in this regard. The job offered by employers did not help them improve their working skills by doing the same tasks every day, as compared to freelancer work where new challenges as well as new opportunities for personal development wait for them every day in the field in which they work.

\section{Analysis of sentiment scores}

In the sentiment score analysis, the NVivo 12 process uses another scoring system. Each word contains the positive or negative sentiment and has a predefined point.

Each sentiment node represents a range on a (sentiment) scale. The sentiment scale from negative to positive. The score for each word determines the sentiment node to which it is encoded. The score of words can be changed if they are preceded by a modifier (for example, more or less) that enhances the sentiment. Words with a score that falls within the neutral range are not coded.

In figure 3, we analysed the words that intensify positive or negative feelings. In our case, the words are: freelancing, vision, financial forecast, risks associated with entrepreneurship, benefits, motivations and the risks they face when moving from freelancing to entrepreneurship.

\begin{tabular}{|c|c|c|}
\hline Sentiment & Q Search All Codes & $\checkmark$ \\
\hline Name & File: & \\
\hline (1) $\Theta$ Negative & & 90 \\
\hline$\oplus+$ Positive & & 147 \\
\hline
\end{tabular}

Fig 3. Sentiment analysis applied on freelancers' narratives Source: data provided by NVivo 12 software

From the sentiment analysis, 90 negative references and 147 positive references have been provided, proving that most respondents have positive feelings about their work as freelancers. We have also observed 90 negative references for an entrepreneurial career for the words financial risk, motivation, vision. 


\section{Limitation of automatic sentiment coding}

NVivo is looking for expressions of sentiment in content. It is important to understand that this tool does not classify content based on sentiment. Not every piece of content is needed and is calculated on a Likert sentiment scale. It looks at the sentiment of isolated words - the context is not taken into account. Like most text analysis tools, NVivo cannot recognize words like sarcasm, double negative, slang, dialect variations, and idioms.

PICBE $\mid 213$

A career in freelancing means flexibility, limitations and the opportunity to do what you know and what you want, in addition to higher financial incomes. Most freelancers began working on freelancing platforms as an option, and then turned freelancing into a career, choosing to manage both their potential and how they would make the most of it. Others have been forced by certain family conditions to choose a career in this regard. Freelancing experience has played an important role in developing entrepreneurial skills due to working with customers, constantly promoting on UPwork platforms, on official freelance websites, or on specialized websites, developing some PR and marketing skills. The opportunity to work on the platforms has become more attractive, giving freelancers the opportunity to organize their time according to their personal lives and to be part of the projects they want.

Most freelancers consider their work to be similar to entrepreneurship, viewing themselves as their own managers and emphasizing the importance of time management.

\section{Conclusions, limitations and further research}

The purpose of the research was to identify the factors underlying the motivation of freelancers to work on the platforms, the risk associated with their work for a long time, and the contextual factors that underlie the decision to move to the next level, that is to develop their own business based on their experience in freelancing.

Research results show that both internal contextual factors such as family conditions and external factors have been identified, including the freedom to work where they want and to manage their own time.

However, freelancers' doors to entrepreneurship remain open if they are genuinely interested in the catalytic effect of managerial training on growth-related entrepreneurial attitudes (Schamp \& Deschoolmeester, 1998). They are constantly looking for new development opportunities, while learning to be organized and meeting different types of clients.

The motivation for an entrepreneurial career benefits from the experience of freelancers gained in their projects, which increases the probability of a managerial attitude and the creation of their own businesses that offer in their turn attractive new jobs.

They consider themselves the CEO of their own brand, they see themselves as marketers as well as their own managers. In this study, freelancers noticed that they faced situations where they had to do marketing, or to distribute their own products and services, situations often encountered in a business. They are aware of the fact that if they do not maintain customer relationships, or if they do not meet the deadline, their revenue may be affected. Managing time and finances is one of the main concerns of freelancers.

The findings of this study outline that freelancers have common points, as they already see themselves as small entrepreneurs and take into account freelancing throughout their life, the reason being the passion they put in their projects. Going through the filter of freelancers' work, we find that they consider themselves small entrepreneurs, working on 
their own, dealing with their own accounting activity and actual delivery to the client, claiming that there are common points between freelancers and entrepreneurs.

Things may differ depending on the level of engagement they offer, their own values that are reflected in the product or service offered. An entrepreneur is a person who creates a company and offers jobs, not necessarily the one who runs it. Both are free to manage their time, which is their greatest asset.

PICBE $\mid 214$

Freelancers can create a strategy for their work, just like an entrepreneur. They are the ones who manage their career, income and decision-making and choose the direction they want to go. In general, however, both must have self-discipline, the ability to cope with uncertainty, the authority to make their own decisions, and to pursue their own strategy and policies.

The main limitation of this study is in line with two concerns related to storytelling as appropriate methodology to analyse social phenomena, as stated by Rooney, Lawlor, and Rohan (2016): the uncertainty that this technique would encourage and enable the production of sufficiently compelling stories and the problem if experiences narrated are rich enough for analysis.

In the future, it is expected that a quantitative analysis of precursors of freelancers' entrepreneurial intent can be conducted to further evaluate the effectiveness of this qualitative approach. In addition, it would be interesting to investigate the performance of the freelancers' turned entrepreneurs through econometric models.

\section{References}

Annink, A., Den Dulk, L., \&Amorós, J. E. (2016). Different strokes for different folks? The impact of heterogeneity in work characteristics and country contexts on work-life balance among the self-employed. International Journal of Entrepreneurial Behavior \& Research, 22(6), 88

Arvidsson, A., Gandini, A., \&Bandinelli, C. (2016). Self-branding amongst freelance knowledge workers, ed Marion Crain, Invisible Labor: Hidden Work in the Contemporary World , University of California Press

Backes-Gellner, U., \& Moog, P. (2013). The disposition to become an entrepreneur and the jacks-of-all-trades in social and human capital. The Journal of Socio-Economics, 47, 5572.

Bazeley, P., \& Jackson, K. (Eds.). (2013). Qualitative data analysis with NVivo. Sage Publications Limited).

Bögenhold, D., Heinonen, J., \& Akola, E. (2014). Entrepreneurship and independent professionals: Social and economic logics. International Advances in Economic Research, 20(3), 295-310.

Born, A., \& Witteloostuijn, A. (2013). Drivers of freelance career success. Journal of Organizational Behavior, 34(1), 24-46.

Burke, A. (2011). The entrepreneurship enabling role of freelancers: Theory with evidence from the construction industry. International Review of Entrepreneurship, 9(3), 1-28.

Burke, A. (Ed.). (2015). The Handbook of Research on Freelancing and Self-Employment. Senate Hall Limited.Economics, No. 06/2016, Retrieved from: http://hdl.handle.net/10419/156261

du Gay, P. (1996), Consumption and Identity at Work, London: Sage.

Handy, C. (1984), The Future of Work : A Guide to a Changing Society, Oxford: Basil Blackwell. 
Handy, C. (1989), The Age of Unreason: New Thinking For A New World, London: Random House Books

Johnson, R. B., Onwuegbuzie, A. J., \& Turner, L. A. (2007). Toward a definition of mixed methods research. Journal of mixed methods research, 1(2), 112-133.

Kitching, J., \&Smallbone, D. (2015). Exploring the UK freelance workforce, Retrieved from:https://www.researchgate.net/profile/John_Kitching/publication/302027852 _Exploring_the_UK_Freelance_Workforce_2015/links/572dd1a908aee022975a58f4 /Exploring-the-UK-Freelance-Workforce-2015.pdf

Luthans, F., \& Youssef, C. M. (2004). Human, social, and now positive psychological capital management:Investing in people for competitive advantage, Management Department Faculty Publications. 154, Retrieved from: https://digitalcommons.unl.edu/managementfacpub/154

Rooney, T., Lawlor, K., \& Rohan, E. (2016, May). Telling tales: Storytelling as a methodological approach in research. In ECRM2016-Proceedings of the 15th European Conference on Research Methodology for Business Management": ECRM2016 (p. 225). Academic Conferences and publishing limited.

Saundry, R., Stuart, M., \&Antcliff, V. (2007). Broadcasting discontent-freelancers, trade unions and the Internet. New technology, work and employment, 22(2), 178-191.

Schamp, T., \&Deschoolmeester, D. (1998). Strategic and operational planning attitudinal changes and the survival and growth of business start-ups revisited: Management training matters. International Journal of Entrepreneurial Behavior \& Research, 4(2), 141-177.

Waite, M. (Ed), (1998), 'Little' Oxford Dictionary (7th Edition), Oxford: Oxford University Press

http://en.wikipedia.org/wiki/Freelancer

https://www.researchgate.net/profile/John_Kitching/publication/302027852_Exploring_t he_UK_Freelance_Workforce_2015/links/572dd1a908aee022975a58f4/Exploringthe-UK-Freelance-Workforce-2015.pdf

https://digitalcommons.unl.edu/managementfacpub/154

https://docs.google.com/forms/d/e/1FAIpQLSc4Ma0vkgaU0faOgFXw89VL4XE9f2v_k2Cq FspK5tF9-9WHw/viewform?usp=sf_link

https://revistacariere.ro/inspiratie/cum-sa/tinerii-romani-nu-mai-stau-opt-ore-la-birousi-devin-freelanceri/

https://help-nv.qsrinternational.com/12/win/v12.1.55-d3ea61/Content/welcome.htm https://en.wikipedia.org/wiki/Ryan_Holmes 